\title{
Risk factors for breast cancer in a pure African society, impact of age, reproductive history, family history and breast feeding
}

\author{
Alice Constance Mensah ${ }^{1,}$, , Joel Yarney ${ }^{2}$, kaku Sagary Nokoe $^{3}$, Samuel Opoku $^{4}$ \\ ${ }^{1}$ Mathematics and Statistics Department, Accra Polytechnic, Accra, Ghana \\ ${ }^{2}$ National Centre for Radiotherapy and Nuclear Medicine, Korle Bu Teaching Hospital, Accra, Ghana \\ ${ }^{3}$ Department of Mathematics, University of Energy and Natural Resources, Suyani, Ghana \\ ${ }^{4}$ Department of Radiography, College of Health Sciences, University of Ghana, Accra, Ghana

\section{Email address:} \\ alicecabakah@yahoo.com (A. C. Mensah)
}

\section{To cite this article:}

Alice Constance Mensah, Joel Yarney, kaku Sagary Nokoe, Samuel Opoku. Risk Factors for Breast Cancer in a Pure African Society, Impact of Age, Reproductive History, Family History and Breast Feeding. Cancer Research Journal. Vol. 2 No. 5 2014, pp. 82-87i: $10.11648 /$ j.crj.20140205.11

\begin{abstract}
Breast cancer is the most frequently diagnosed cancer and the leading cause of cancer death in female's worldwide. The objective of the study was to identify the extent to which selected demographic, hormonal and reproductive factors influence the cause of breast cancer using the logistic regression technique to determine the risk of getting the disease. Two thousand three hundred and ninety seven (2397) women were sampled for the study from the Korle-bu Teaching Hospital, of which 1022 (42.64\%) were diagnosed with breast cancer between the periods January 2002 to December 2008. Breast feeding, late menarche, contraceptive usage, and time interval between age at menarche and age at menopause all decreased the risk of breast cancer development $(\mathrm{OR}=2.306,<0.0001)$. Later age at menopause on the other hand increased the risk of breast cancer development. It is recommended that governmental or nongovernmental organizations improve on health education/campaigns about breast cancer to create awareness and reduce mortality.
\end{abstract}

Keywords: Breast Cancer, Risk Factors, Reproductive History, Family History, Breast Feeding and Logistic Regression

\section{Introduction}

Breast cancer impacts on women's health and development across the lifecycle, causing morbidity and mortality. Deaths of women from breast cancer during their most productive years (40-60 years) could result in tragedy for families, food insecurity, children withdrawn from school, increased work burden on children and loss of assets, (WHO, 2006). Breast cancer is a malignant tumour in the glandular tissues of the breast. Such tumours, also called carcinomas, and are formed when the processes that control normal cell growth breaks down, enabling a single abnormal cell to multiply at a rapid rate. Breast cancer consists of several sub-types. It can be diagnosed at different stages of development and can grow at different rates. Breast cancer is a complex disease and it is difficult to predict outcomes (Carey et al., 2006). Breast cancer is a malignant tumour in the glandular tissues of the breast.
Such tumours, also called carcinomas, form when the processes that control normal cell growth breaks down, enabling a single abnormal cell to multiply at a rapid rate. Breast cancer is not one single disease and there are several types of breast cancers. It can be diagnosed at different stages of development and can grow at different rates. Breast cancer is a complex disease and it is difficult to predict what course it will take, (Carey et al., 2006).

Breast cancer is the most common type of lifethreatening cancers, and the second most common cause of cancer-related deaths of women in the Western world (American Cancer Society, 2008). In Ghana, breast cancer is now the most common malignant disease in women and accounts for the majority of cancer related deaths (Wiredu et al., 2006). In all parts of the world today, cancer of the breast is a stark reality. For many years people have perceived breast cancer as a frightening disease surrounded by fears and myths. In $199612.8 \%$ of all admissions for malignant neoplasms to the Korle $\mathrm{Bu}$ Teaching hospital 
were for breast cancer, (Biritwum et al., 2000)

There are concerns about increasing rate of breast cancer among young people in Ghana. In addition to the fact that the incidence of the disease appears to be on the increase, late presentation with poor outcomes of treatment is the hallmark of breast cancer in most developing countries including Ghana, (Opoku et al ,2012). It is also disturbing that the average age at diagnosis for breast cancer in Ghana is 46.29 years with a range of 26 to 80 years as compared to an average age of over 65 years in Europe and America,(Anim 1993; NCRNM, 2007). In addition, Ghanaian women tend to develop breast cancer at a younger age (Ghartey 2001).

Presently about 2000 women are diagnosed of breast cancer each year in Ghana and the forecast is that about 3000 women in Ghana will develop breast cancer each year, (WHO, 2008). Studies have shown that certain factors are intimately associated with breast cancer some of which are amenable to change. For this study, established risk factors that are well described in the breast cancer literature( Chlebowski et al; 2005; Hal et al, 20051; GarciaClosas et al, 2006), and commonly acknowledged by major cancer organizations, such as the American Cancer Society and the Susan G. Komen Foundation were considered. These factors include reproductive history, family history of breast cancer, menstrual history and hormone use. The influence of anthropometric measures on breast cancer risk has been the subject of many studies (Sasieni et al,2011; Anyanwu, 2008; Jatoi, 1999; Burke, 2000; Tessaro et al,2001; Kahlenborn et al,2008; Casey et al, 2008; Lower, 2008; Ansink and Burger 2007; Hoffman et al., 2000). However, these findings were derived from studies conducted mainly in Western countries. The contribution of well-established risk factors to breast cancer among developing countries remains unclear.

Therefore, this study focused on examining the extent to which selected demographic, hormonal and reproductive factors influence the cause of breast cancer by using a logistic regression model and to determine the likelihood of one's risk of getting the breast cancer based on the logistic regression model.

Since breast cancer elicits many fears, findings of this study can provide useful information and knowledge to help the victims make the best decisions concerning their care. Heightened awareness of breast cancer risk will lead to increase in women undergoing mammography screening leading to the detection of cancers in earliest stages and results in improved survival rates afflicted people.

\section{Methodology}

\subsection{Study Design}

This is a retrospective cohort study comprised all Ghanaian women who reported at the Breast Clinic of the Korle bu Teaching Hospital (KBTH) or its cancer centre between January 2002 and December 2008, KBTH is the leading national referral centre in Ghana, receiving patients from across the country, but mostly in the southern part. The Breast Clinic at Korle Bu Teaching Hospital is a walkin clinic that admits women who desire to be screened for breast cancer without asking for a referral note.

\subsection{Data Source}

The cases and controls were sampled from the Records Section of the Cancer centre and the Breast Clinic respectively of the $\mathrm{KBTH}$. The records unit is a departmental registry where registered cancer cases for treatment are kept. Sources for the data included, abstract of hospital records for the cases and in person interviews conducted by the female registered nurses of the Breast walk-in Clinic for controls. The nurse- interviewer elicited information on demographic and potential breast cancer risk factors, including family history of breast cancer or other cancers, menstrual and reproductive history, sociodemographic and lifestyle characteristics using a questionnaire.

This research has been assessed and approved by the School of Allied Health Sciences, University of Ghana Ethics and Protocol Review Committee with identification number: SAHS - ET./AA/1A/2013-2014.

\subsection{Inclusion Criteria}

All Ghanaian women who visited the Korle-bu Teaching hospital, National Centre for Radiotherapy and Nuclear Medicine and the walk in clinic for breast screening, were eligible cases. All eligible cases and controls were anonymized. Cases were required to have histologically proven breast cancer consisting of invasive ductal carcinoma, invasive lobular carcinoma, ductal carcinoma in-situ and lobular carcinoma in-situ.

\subsection{Exclusion Criteria}

Clients with incomplete information other histological varieties other than those listed above and aged less than twenty (20) years were excluded.

Nine key variables on breast cancer risk factors, which provided the required measures on data, were identified as: age at first visit; family history of breast cancer; age at menarche; age at menopause; age at first child; hormone based contraceptive usage; parity and breastfeeding.

Descriptive statistics of frequencies and percentages was used to describe the categorical variables.. Multivariate analysis was performed using binary logit regression. SAS version 9.0 (Cary, NC 27513 USA) was used for the analysis. P - Value $<0.05$ was considered significant.

\subsection{Calculation of Risk}

Suppose $Y$ is the random binary variable whose value is zero or one; where zero and one represents two different classes to which a subject may belong. The probability that $Y=1$ is denoted by $\mathrm{p}$, that is, $P(Y=1)=p$, then 
$P(Y=0)=1-p$. The ratio of $p$ to $1-p$ is referred to as the odds in favour of the event that $Y=1$ and is given by:

$$
\operatorname{odds}(Y=1)=\frac{p}{1-p}
$$

The odds against an event is the reciprocal of the odds in favour of the event. Odds and probabilities provide the same information, but in different forms. The odds in the above equation may be converted into probability as

$$
p=\frac{\operatorname{odds}(Y=1)}{1+\operatorname{odds}(Y=1)}
$$

It may be more relevant to consider the natural logarithm of the value of the odds obtained. Thus,

$$
\ln [\operatorname{odds}(Y=1)]=\ln \frac{p}{1-p}
$$

which is a function of the probability, $p$. This function of $p$ may be expressed as a linear combination of $k$ independent random variables $\left(X_{1}, X_{2}, X_{3}, \cdots, X_{k}\right)$. The function of $p$ is thus known as the $\operatorname{logit}(p)$. Thus,

$$
\log \operatorname{it}(p)=\ln \frac{p}{1-p} .
$$

The $\operatorname{logit}(p)$ equation is given as or, in a matrix form

$$
\ln \frac{p}{1-p}=\beta X
$$

where, $\beta^{\prime}=\left(\beta_{o}, \beta_{1}, \beta_{2}, \beta_{3}, \cdots, \beta_{k}\right)$ is a vector of $k+1$ coefficients of the logistic regression model and $\mathrm{X}=\left(1, X_{1}, X_{2}, X_{3}, \cdots, X_{k}\right)$ is a vector of independent variables that are a combination of categorical and continuous variables. In either of the forms given, the odds is then given as

$$
\operatorname{odds}\left[Y=\frac{1}{\left(X_{1}, X_{2}, X_{3} \ldots X_{k}\right)}\right]=\frac{p}{1-p}
$$

where $p$ is the probability of the event $Y=1$ given the values of the independent variables, $\left(X_{1}, X_{2}, X_{3}, \cdots, X_{k}\right)$. As can be seen the logarithm of the odds can be modeled as a linear function of the independent variables, and is equivalent to a multiple regression equation with the logarithm of the odds as the dependent variables.

\section{Results}

Two thousand three hundred and ninety seven (2397) women were sampled for the study, of which $42.64 \%$ were diagnosed with breast cancer between the periods $1^{\text {st }}$ January 2002 to $31^{\text {st }}$ December 2008. The outcome variable used for the study was binary. The value one represented the case and zero the control. The data was collected for 1375 controls and 1022 cases, for all the risk factors of the study as noted earlier. The ages of the women at first visit
(AG) ranged from 20 - 92 years, with a mean age of 43.51 years consistent with observations by (Anyanwu, 2008). The highest incidence rate occurred in age group $40-49$ years $(34.34 \%)$. This indicates that, that Ghanaian women present breast cancer at a significantly younger age. The menarche (MN), mean age at first child (AFC) and menopause (MP), were 15.17, 23.83 and 47.55 years respectively. Parity (PT) ranged from $0-12$ children with a $(2.47 \pm 2.31)$ and a median of 2 . Similarly age interval between menarche and menopause (APM), ranged from 8 45 years with a mean $( \pm \mathrm{SD})$ value of $32.38 \pm 4$ and median 33 years.

The peak age at presentation of highest incidence rate occurred in age group 40 - 49 years. This indicates that, Ghanaian women present breast cancer at a younger age as compared to women in the developed world, (Adebamowo and Ajayi, 2000; Schatzkin et al, 1987, Muyberry and Toddard-Wright, 1992; Bowen et al, 2008). This is depicted in table 1 above.

Table 1. Frequency Distribution of women with Breast Cancer by Age

\begin{tabular}{lll}
\hline Variables & Frequency & \% Frequency \\
\hline AG $: 20-29$ & 26 & 2.54 \\
$30-39$ & 200 & 19.57 \\
$40-49$ & 355 & 34.74 \\
$50-59$ & 275 & 26.91 \\
$60-69$ & 120 & 11.74 \\
$70+$ & 46 & 4.5 \\
\hline
\end{tabular}

Table 2. Frequency Distribution of all the Women by Reproductive Factors

\begin{tabular}{llll}
\hline Variables & Frequency & \% Frequency & $\begin{array}{l}\text { \% with Breast } \\
\text { cancer }\end{array}$ \\
\hline MN: $<13$ & 226 & 9.43 & 47.79 \\
$\geq 13$ & 2171 & 90.57 & 42.1 \\
AFC: $<24$ & 906 & 37.8 & 46.36 \\
$\geq 24$ & 1491 & 62.2 & 40.38 \\
MP: $<48$ & 2028 & 84.61 & 38.91 \\
$\geq 48$ & 369 & 15.39 & 63.14 \\
PT: 0 & 540 & 22.53 & 30 \\
$1-4$ & 1483 & 61.87 & 43.76 \\
$\geq 5$ & 374 & 15.6 & 56.42 \\
CTRP: Yes (ever used) & 292 & 12.18 & 27.71 \\
No (never used) & 2105 & 87.82 & 44.85 \\
FH: Yes & 138 & 5.76 & 44.92 \\
No & 2259 & 94.24 & 42.5 \\
BF: Yes & 850 & 35.46 & 17.18 \\
No & 1547 & 64.54 & 56.63 \\
\hline
\end{tabular}

$\mathrm{MN}=$ Age at menarche; $\mathrm{AFC}=$ Age at first child; $\mathrm{MP}=$ Age at menopause $\mathrm{PT}=$ Parity $; \mathrm{CTRP}=$ contraceptive $\mathrm{use} ; \mathrm{FH}=$ family history $; \mathrm{BF}=$ Breast feeding.

The analysis revealed that, there was a history of breastfeeding in $35.46 \%$ of the women of which $17.18 \%$ had breast cancer. Women with no history of breastfeeding had $56.63 \%$ being diagnosed with breast cancer. Age at menarche for $9.43 \%$ of the women was below 13 years of age and $47.79 \%$ of them were suffering from breast cancer. Of the remaining $90.57 \%$ who had their first menstruation 
on or after 13 years $42.10 \%$ were diagnosed of having breast cancer. With respect to parity, $22.53 \%$ of the women in the study were nulliparous, $61.87 \%$ had $1-4$ children and remaining $15.60 \%$ had more than 5 children. Out of these $30 \%, 43.76 \%$ and $56.42 \%$ were having breast cancer respectively. Contraceptive use was found in $12.18 \%$ of the women. Of the remaining women who did not use contraceptive, $47.22 \%$ had the disease. Age at menopause affects breast cancer development, breast cancer occurs more among those who attain menopause on or after 48 years than those whose menopausal age is less than 48 years in the study population.

Table 3. Frequency Distribution of Women with Breast Cancer by Reproductive Factors

\begin{tabular}{lll}
\hline Variables & Frequency & \% Frequency \\
\hline MN: $<13$ & 108 & 10.57 \\
$\geq 13$ & 913 & 89.33 \\
AFC: $<24$ & 420 & 41.1 \\
$\geq 24$ & 602 & 58.9 \\
MP: $<48$ & 789 & 77.2 \\
$\geq 48$ & 233 & 22.8 \\
PT: 0 & 162 & 15.85 \\
$1-4$ & 649 & 63.5 \\
$\geq 5$ & 211 & 20.65 \\
CTRP: Yes & 78 & 7.63 \\
No & 944 & 92.37 \\
FH: Yes & 62 & 6.07 \\
No & 960 & 93.93 \\
ALC: Yes & 47 & 4.6 \\
No & 975 & 95.4 \\
BF: Yes & 146 & 14.29 \\
No & 876 & 85.71 \\
\hline
\end{tabular}

The model looked at nine variables as shown in Table 3. The explanatory variables Parity, family history and age at

first child were found to be insignificant variable and as such were dropped. Family history had an odds ratio of 1.368 which indicated an increased risk of $36.8 \%$ of developing breast cancer for those with family history as compared to those who had no family relation suffering from breast cancer. Thus, there is an increased risk of breast cancer if the woman has a family history of cancer. For each increase in full term pregnancy, the odds of being at risk in developing breast cancer increased from 1 to 1.088 , which means multiparity increased the risk of developing breast cancer according to this study $8.8 \%$.

Table 4. Stepwise logistic analysis of significant risk factors of breast cancer for all the women

\begin{tabular}{lllll}
\hline Parameter & $\hat{\beta}$ & $e^{\hat{\beta}}$ & p-value & 95\% confidence Limits \\
\hline MN & -0.7352 & 0.479 & 0.0001 & $0.343-0.675$ \\
AG & 0.0407 & 1.042 & 0.0001 & $1.032-1.051$ \\
MP & 0.8353 & 2.306 & 0.0001 & $1.626-3.279$ \\
CTRP & -0.6813 & 0.506 & 0.0001 & $0.373-0.683$ \\
BF & -1.7081 & 0.181 & 0.0001 & $0.146-0.224$ \\
APM & -0.1223 & 0.885 & 0.0001 & $0.859-0.912$ \\
\hline
\end{tabular}

$\mathrm{AG}=$ age at first Visit; APM = age interval between menarche and menopause

\section{The Logit Model}

According to the analysis the logit model with the significant variables is as follows:

$$
\begin{aligned}
\mathrm{g}(\mathrm{x})= & 2.9998-0.7325 \mathrm{MN}+0.0407 \mathrm{AG}+0.8353 \mathrm{MP}- \\
& 0.6813 \mathrm{CTRP}-1.7081 \mathrm{BF}-0.1223 \mathrm{APM}
\end{aligned}
$$

hence the logistic regression model developed in the study is

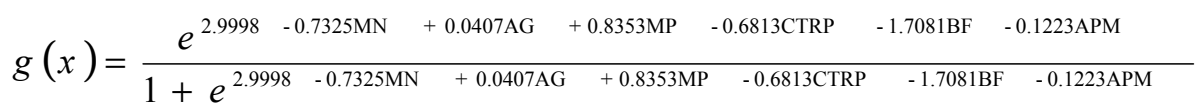

\section{Discussion}

Further analysis indicated, an odds ratio of 0.479 for age at menarche indicating a decrease in risk of breast cancer development by $52.1 \%$ in women with menarche on or after 13 years. Some studies have indicated a protective effect for late menarche (Bowen et al, 2008; Hsieh et al, 1990; Brinton, 1997; Kvale and Heuch, 1988 ). Thus, for a year increase in age, the risk of developing breast cancer increased by $4.2 \%$ and this variable was significant. Age at Menopause with an odd ratio of 2.306 indicates an increased risk of breast cancer among those who attained menopause on or after 48 years than those whose menopausal age was less than 48 years in the study population. This is consistent with studies reporting of an increasing risk of breast cancer with increasing age at menopause, (Talamin et al,1996). The occurrence of breast cancer was 0.506 as frequent among those who used contraceptives. Contraceptive use had an impact on the risk of developing breast cancer. Women who used contraceptives were $49.4 \%$ less likely to develop breast cancer than women who did not use contraceptives. This result is consistent with some previous studies done, and inconsistent with the following studies, (Burke, 2000; Tessaro et al,2001; Kahlenborn et al,2008; Casey et al, 2008; Lower, 2008; Ansink et al, 2007; Briton et el, 1998). There is an inverse relationship between the risk of developing breast cancer and breast feeding. Thus, the more one breast feeds the less likely she is to develop breast cancer by $81.9 \%$. Breast feeding has been observed to be protective against breast cancer development, (Beral, 2002) which is consistent with the findings of this study. The time interval between age at menarche and age at menopause indicated a positive relationship between the risk of developing breast cancer and the period. An odd ratio of 0.885 indicated a decreased risk of developing breast cancer by $11.5 \%$ per year. 


\section{Conclusion}

Using the dichotomous logistic regression with multiple predictor variables, the model indicates that, risk factors associated with breast cancer are: age of the woman, age at menopause, breastfeeding, age at menarche, age interval between menarche and menopause and contraceptive use ( $p$ $<0.05$ ), contribute to breast cancer development.

\section{References}

[1] Adebamowo C. A. Ajayi O. O.(2000). Breast Cancer in Nigeria.West Afr J Med. Jul-Sep;19(3):179-91.

[2] Albrektsen G, Heuch I, Kvale G.(1995). The short-term and long-term effect of a pregnancy on breast cancer risk: a prospective study of 802,457 parous Norwegian women. Br J Cancer.; 72:480-4.

[3] American Cancer Society(2009), Cancer Facts \& Figures for African Americans 2009-2010.

[4] Anim J. T.(1993). Breast cancer in sub-Saharan African Women. Afr J Med Med Sci. Mar;22(1):5-10.

[5] Ansink A. C., Burger C. W.(2007). Oral contraceptives and breast cancer risk. J Clin Oncol. Nov 20;25(33):5327.

[6] Anyanwu S. N. C.(2008). Temporal trends in breast cancer presentation in the third world. J Exp Clin CancerRes.; 27(1): 17

[7] Archampong E. Q.( 1977). Breast Cancer. Ghana Med $J . ; 16(2): 63$.

[8] Asumanu E, Vowotor R, Naaeder S. B.( 2000). Pattern of breast diseases in Ghana. Ghana Med J.;34:206-209.

[9] Badoe E. A., Baako B. N.( 2000). The Breast. In: Badoe EA, Archampong EQ, da Rocha-Afodu, editors. Principles and Practice of Surgery including pathology in the tropics. Accra: Department of Surgery, University of Ghana Medical School;. pp. 449-477

[10] Beral V,. 2002Breast cancer and breastfeeding: collaborative re-analysis of individual data from 47 epidemiological studies in 30 countries, including 50,302 women with breast cancer and 96,973 women without the disease. Lancet;360:187-195

[11] Biritwum R. B., Gulaid J., Amaning A. O.(2000). Pattern of diseases or conditions leading to hospitalisation at the Korle Bu Teaching hospital. Ghana Med J.;34:197-205.

[12] Bowen R. L., Duffy S. W., Ryan D. A.,. Hart I. R., and Jones J. L.(2008) "Early onset of breast cancer in a group of British black women," British Journal of Cancer, vol. 98, no. 2, pp. 277-281,.

[13] Brinton L. A., Brogan D. R., Coates R. J., Swanson C. A., Potischman N., Stanford J. L.(1998) Breast cancer risk among women under 55 years of age by joint effects of usage of 36 oral contraceptives and hormone replacement therapy. Menopause. Fall;5(3):145-51.

[14] Brinton, L. A. (1997) Hormone replacement therapy and risk for breast cancer. Endocrinology \& Metabolism Clinics of North America, 26, 361-78.
[15] Burke W.(2000). Oral contraceptives and breast cancer: A note of caution for high-risk women. JAMA. Oct $11 ; 284(14): 1837-8$.

[16] Carey L.A., Perou C.M., Livasy C.A., (2006) Race, breast cancer subtypes, and survival in the Carolina breast cancer study. JAMA.;295:2492-2502.

[17] Casey P.M., Cerhan J.R., Pruthi S. (2008). Oral contraceptive use and risk of breast cancer. Mayo Clin Proc. Jan;83(1):86-90Chen V. W., P. Correa, R. J. Kurman et al., "Histological characteristics of breast carcinoma in blacks and whites,"Cancer Epidemiology Biomarkers and Prevention, vol. 3, no. 2, pp. 127-135, 1994.

[18] Chlebowski R. T., Chen Z., Anderson G. L., (2005). Ethnicity and breast cancer: factors influencing differences in incidence and outcome. J Natl Cancer Inst.; 97:439-48.

[19] Colditz G., Baer H.J, Tamimi R. M.( 2006) editor. Breast Cancer in: Cancer Epidemiology and Prevention: Oxford University Press;

[20] Colditz, G. A., W. C. Willett, D. J. Hunter,M. J. Stampfer, J. E. Manson, C. H. Hennekens, B. A. Rosner, and Speizer F. E. (1993), Family History, Age, and Risk of Breast Cancer: Prospective Data From the Nurses' Health Study. Journal of Clinical Medicine 270(3): 338-343.

[21] Ferlay J, Bray F, Pisani P, Parkin D. M.(2001) GLOBOCAN 2000: Cancer Incidence, Mortality and Prevalence Worldwide, Version 1.0. IARC Press. Lyon: IARC Cancer Base No. 5;

[22] Ferlay J., Shin H. R., Bray F., Forman D., Mather C. and. Parkin, D. M.(2010) "GLOBOCAN 2008 v1.2, Cancer Incidence and Mortality Worldwide. IARC Cancerbase No, 10," International Agency for Research on Cancer, Lyon, France,

[23] Forouzanfar M. H, Foreman K.J , Delossantos A.M., Lozano R., Lopez A.D., Murray C. J. L., Naghavi M. (2011). Breast and cervical cancer in 187 countries between 1980 and 2010: a systematic analysis; The Lancet, Volume 378, issue 9801,:1461 - 1484, doi:10.1016/S01406736(11)61351-2

[24] Garcia-Closas M, Brinton L. A., Lissowska J., Chatterjee N., Peplonska B., Anderson W. F.( 2006). Established breast cancer risk factors by clinically important tumour characteristics. Br J Cancer.; 95:123-9.

[25] Ghartey F. N.(2001). A Cross-Sectional View of Breast Cancer in Ghana.; Mammocare, Ghana.

[26] Gui, G. P. H., Hogben R. K. F., Walsh G., A'Hern R., and Eeles R. (2001). The incidence of breast cancer from screening women according to predicted family history risk: does annual clinical examination add to mammography? European Journal of Cancer 37(13): 1668-1673.

[27] Hall I. J., Moorman P. G., Millikan R. C., Newman B.(2005). Comparative analysis of breast cancer risk factors among African-American women and White women. Am J Epidemiol.; 161:40-51.

[28] Helmrich, S. P., Shapiro,S., Rosenberg L. Kaufman D. W, Scone D. Bain C, Miettinen O, Stolley P. D,. (1983). Risk Factors for Breast Cancer. Am J Epidemiol, 117:35-45 
[29] Hsieh,C. C, Trichopoulos D, Katsouyanni K, Yuasa S. (1990). Age at menarche, age at menopause, height and obesity as risk factors for breast cancer: association and interactions in an international case-control study. Int $J$ Cancer, 46:796-800

[30] Jatoi, I. (1999). Breast cancer screening. American Journal of Surgery, 177, 518-524.

[31] Kahlenborn C. (2008). Modugno F, Severs WB. Oral contraceptives and breast cancer. Mayo Clin Proc. Jul;83(7):849-50.

[32] Kelsey J. L, Horn-Ross P. L.(1993). Breast cancer: magnitude of the problem and descriptive epidemiology. Epidemiol Rev. ;15:7-16.

[33] Kvale G and Heuch I (1988). Menstrual factors and breast cancer risk. Cancer, 62:1625 - 31

[34] La Vecchia C, Negri E,Palli D, Bruzzi P, Talamini R Dardanoni G. Decarli A, Franceschi S., (1992). The role of age at menarche and at menopause on breast cancer risk: combined evidence from four case-control study. Am Oncol $3: 625-9$.

[35] Lee HP, Gourley L, Duffy SW, Esteve J, Lee J Day NE, (1992). Risk factors for breast cancer by age and menopausal status: a case-control study in Singapore. Cancer causes and control, 3:313-22

[36] Lower J.(2008). Hormonal contraceptives--an ongoing matter of research. Bundesgesundheitsblatt Gesundheitsforschung Gesundheitsschutz. Jul;51(7):779-81.

[37] Muyberry R. M., Stoddard-Wright C.(1992). Breast cancer risk factors among black and white women: similarities and differences. AmJEpidemioll;136:1445-1456

[38] NCRNM.(2007). Annual Report National Center for Radiotherapy and Nuclear Medicine, Korle Bu Teaching Hospital.; Accra Ghana

[39] Negri, E., Brage C., La Vecchia C., Franceschi, S., Filiberti R., Montella M.,Falcini F., Conti, E. and Talamini R. (1998). Family history of cancer and risk of colorectal cancer in Italy. British Journal of Cancer, 77(1), 174-179.

[40] Opoku S. Y., Benwell M. and Yarney J. (2012). Knowledge, attitudes, beliefs, behaviour and breast cancer screening practices in Ghana, West Africa. Pan African Medical Journal.; 11:28 - ISSN 1937-8688.
[41] Paffenbarger R. S., Kompert J. B., Chang H. (1980). Characteristics that predict risk of breast cancer before and after the menopause. Am J Epidemiol, 112:258-68

[42] Rawal, R., Bertelsen L., and Olsen J. H(2006). Cancer incidence in first-degree relatives of a population-based set of cases of early-onset breast cancer. European Journal of Cancer 42(17): 3034-3040.

[43] Romieu I, Hernadez-Avila M, Lazeano E, Lopez L, Romero-Jaime R (1996). Breast cancer and lactation history in mexican women. Am J Epidemiol, 143:543-52.

[44] Sasieni P. D, Shelton J, Ormiston-Smith N. J, Thomson C. S, Silcocks P. B.(2011). What is the lifetime risk of developing cancer: The effect of adjusting for multiple primaries,

[45] Schatzkin A, Palmer JR, Rosenberg L,. Risk factors for breast cancer in black women. $J$ Natl Cancer Inst 1987;78:213 - 7 .

[46] Swerdlow A.J., De Stavola B. L., Floderus B., Holm N. V., Kaprio J, Verkasalo P. K,. Risk factors for breast cancer at young ages in twins: an international population-based study. J Natl Cancer Inst. 2002; 94: 1238-46.

[47] Talamin R, Franceschi S, La Vecchia C, Negri E, Brosa L, Montella M, Faleini F,nConti E, Rossi C (1996). The role of reproductive and menstrual factors in cancer of the breast before and after menopause. Eur J cancer, 32A:303-10.

[48] Tessaro S, Beria J. U., Tomasi E, Barros A. J.(2001). Oral contraceptive and breast cancer: a case-control study. Rev Saude Publica. ;35(1):32-8.

[49] Trichopoulos D, Macmahon B, Cole P, (1972). Menopause and breast cancer $J N C I, 48: 605-13$

[50] WHO (2008) Global Burden of Disease 2004 update. http:// www.who.int/healthinfo/global_burden_disease/estimates_c ountry/en/index.html.

[51] Wiredu E. K., Armah H. B.(2006). Cancer mortality patterns in Ghana: a 10 -year review of autopsies and hoapital mortality. BMC Public Health; 6:159-165.

[52] Wu SC, Hotes J, Fulton JP, Chen VW, Howe HL, Correa C. (2002). Cancer in North America, 1995-1999. Volume III: NAACCR Combined Cancer Incidence Rates. Springfield, IL: North American Association of Central Cancer Registries. 